\title{
Adubação de nitrogênio, fósforo e potássio no rendimento de Physalis spp.
}

\author{
Nitrogen, phosphorus and potassium fertilization \\ results on Physalis spp. yeld
}

\author{
Márcia Thomé ${ }^{[a]}$, Flora Osaki ${ }^{[b]}$ \\ [a] Engenheira agrônoma, Curitiba, PR - Brasil, e-mail: marciaagro@hotmail.com \\ [b] Engenheira agrônoma, professora Doutora do Departamento de Agronomia da Pontifícia Universidade Católica do Paraná \\ (PUCPR), Curitiba, PR - Brasil, e-mail: rk_osaki@netpar.com.br
}

\section{Resumo}

O objetivo do presente trabalho foi estudar o efeito de diferentes níveis de adubo no rendimento de três variedades de Physalis spp. O trabalho foi conduzido em Porto Amazonas, PR. O preparo do solo foi feito por capina manual e com aplicação de $2 \mathrm{t} \mathrm{ha}^{-1}$ de calcário 30 dias antes do plantio. Os dados de emergência, surgimento primeiro botão floral e do primeiro fruto, altura de planta e início da maturação dos frutos foram obtidos por diagnóstico visual diário. A variável emergência compreendeu da semeadura até o momento em que $50 \%$ das plantas por bandeja emergiram. O peso médio por fruto (g), rendimento médio de frutos por planta $\left(\mathrm{kg} \mathrm{pl}^{-1}\right)$ e rendimento médio por área $\left(\mathrm{t} \mathrm{ha}{ }^{-1}\right)$ consistiu na coleta de dez plantas/parcela. Os frutos colhidos foram colocados em sacos de papel e identificados. Os frutos que apresentaram boa qualidade foram pesados em balança de precisão e os descartados foram pesados e compuseram as perdas por variedade $\left(\mathrm{kg} \mathrm{ha}^{-1}\right)$. O delineamento experimental foi o de blocos ao acaso em parcelas subdivididas com 12 tratamentos, sendo o fator variedade (Physalis angulata, P. peruviana e $P$. oxicarpa) aplicado às parcelas e o fator adubação aplicado às subparcelas (quatro níveis). $\mathrm{O}$ fator variedade foi analisado pelo Teste de Tukey, com significância de 95\%, e os níveis de adubo, pela análise de regressão. Concluiu-se que a adubação NPK mostrou diferenças entre as curvas de respostas para as variedades estudadas; estas não mostraram diferenças para o peso de fruto, rendimento por planta e por hectare.

Palavras-chave: Physalis. Adubação. Variedades.

\section{Abstract}

TheThe objective of this paper was to study the effect of fertilizer levels on three Physalis spp. varieties income. The experiment was conducted in Porto Amazonas city, Parana State. Soil preparation was made by means of manual weeding and $2 \mathrm{tha}^{-1}$ of calcareous application 30 days before planting. The 
emergence, first flower bottom showing, first fruit arise, plant height and fruit maturation beginning data were obtained visually, been observed daily. The variable emergence was considered as period between seedling and 50\% plant emergence in winnowing basket. The average weight per fruit $(g)$, average fruit income per plant $\left(\mathrm{kg} \mathrm{pl}^{-1}\right)$ and average income per area $\left(t h a^{-1}\right)$ data were collected from ten plants per plot. The harvested fruits were placed in paper bags and identified, in which it was weighed in precision scale the good quality ones. Dropped fruits were also weighed, making up losses range $\left(\mathrm{kg} \mathrm{ha}^{-1}\right)$. The experimental design used was randomized blocks in split plot with 12 treatments, in which the variety factor (P. angulata, P. peruviana e P. oxicarpa) was applied to the plots and the fertilizer level factor was applied to the splits (4 levels). The variety factor was analyzed by Tukey Test with 95\% confidence level, and to the fertilizer levels it was used regression analysis. It was concluded that the NPK fertilization resulted in differences between responses curves, to the studied varieties, in which was not observed significant differences to the fruit weight, income per plant and income per hectare data.

Keywords: Physalis. Fertilization. Varieties.

\section{Introdução}

A fisalis é uma planta da família das Solanaceas e do gênero Physalis, e compreende mais de cem espécies conhecidas. Originária da Amazônia e dos Andes, possui variedades cultivadas na América, Europa e Ásia. Entre elas podem ser citadas a P. angulata L., P. peruviana, P. pubescens, P. primorosa, P. ixocarpa e P. philadelphia.

No Brasil, a espécie nativa é a $P$. angulata, que possui um sabor levemente ácido e adocicado, muito versátil, consumida ao natural ou usada na preparação de doces, geleias, sorvetes, bombons, licores e em molhos de saladas e carnes (FROTA, 2005). A fisalis brasileira (P. angulata L.) é conhecida como planta daninha ou medicinal, com nomes bem populares como bucho-de-rã, joá-de-capote, camambu, mata-fome, bate-testa e balão-rajado. É uma planta anual, herbácea, ereta, ramificada, de caule semissuculento e glabro, com a parte comestível protegida por uma delicada folha em formato de balão semelhante ao papel de arroz. É comum encontrá-la em quase todo território nacional, onde infesta principalmente lavouras, pomares, jardins e hortas. Suas sementes apresentam grande poder de germinação, vegetam em solos ricos em matéria orgânica, bem supridos de umidade e tolerantes a certo grau de sombreamento (LORENZI, 2000).

A P. peruviana L. é uma planta arbustiva e perene, originária dos Andes, entre o Chile e o Peru, que pode atingir a altura de 1,0 a 1,5 m. O ramo principal, após produzir de 8 a 12 nós, bifurca-se naturalmente, originando os ramos que irão produzir. Nos ramos produtivos desenvolve-se, em cada nó, uma gema vegetativa e uma gema floral (BRIGUENTI; MADEIRA, 2007).

A duração da floração é de dois a três dias e as flores são polinizadas por insetos ou pelo vento, ocorrendo também a autopolinização. O fruto é uma baga globosa, contendo de 100 a 300 sementes, e seu desenvolvimento dura de 60 a 80 dias (BRIGUENTI; MADEIRA, 2007).

Alguns autores relatam que o início da produção ocorre a partir do quarto ou quinto mês e se estende por um período de seis meses quando é feito um bom trato cultural (BRANDÃO, 2007). Para Briguenti e Madeira (2007), a primeira colheita ocorre após seis ou sete meses de semeadura, podendo se prolongar até dois anos com o manejo adequado, devendo tomar cuidados desde a colheita até a venda ao consumidor.

O ciclo completo da semeadura até a colheita dura entre oito a nove meses. A colheita começa quando as frutas apresentam coloração alaranjada e quando a capa que envolve a fruta fica com a cor amarelo pardo (GUERREIRO, 2006).

O mesmo autor destaca que as possíveis pragas que eventualmente possam atacar a cultura são pulgões, mosca-branca, trips e nematóides, e as doenças são mofo-cinzento e fusarium.

Por ser uma planta rústica, pode tolerar ligeiras geadas e demonstra ligeira resistência à deficiência hídrica (PHYSALIS, 2007). 
De acordo com pesquisas já realizadas, a fisalis é sensível em condições de umidade alta, devendo-se tomar o cuidado com encharcamentos. O excesso de água pode causar plantas amareladas e de pouca folhagem, facilitando a queda das folhas, flores e frutos. Antes de plantar é aconselhável realizar a análise de solo, que deve ser preparado como as recomendações para o tomate (BRANDÃO, 2007; SL, 2007). Os solos recomendados para a cultura são aqueles que apresentam estrutura granular, areno-argiloso, com elevado teor de matéria orgânica e pH entre 5,5 e 6,8 (BRANDÃO, 2007; ESTAÇÃO EXPERIMENTAL SERRA LUIZA, 2007; PHYSALIS, 2007).

O crescimento da $P$. peruviana pode ocorrer em qualquer solo bem drenado, mas prefere solos arenosos. A produção de folhas é estimulada em solos férteis, mas pode ocorrer dificuldades na maturação dos frutos. De fato, o rendimento da cultura poderá ser alto em solos arenosos e pobres. Em situações de estiagem as plantas podem ficar dormentes (GUERREIRO, 2006).

A quantidade de adubo a ser aplicada deve ser determinada com base nos resultados da análise do solo e nos boletins-aproximação de cada região. Na maioria desses boletins não existem recomendações para a cultura de fisalis; utiliza-se então a recomendação para o tomateiro. A exigência de nutrientes é muito grande, embora a quantidade de nutrientes retirada seja relativamente baixa. Por exemplo, os fertilizantes fosfatados têm uma taxa de absorção de apenas 10\%, ficando o restante no solo na forma residual (SILVA et al., 2007).

De modo geral, a recomendação é de 80-120 kg de N/ha, 300-450 kg de $\mathrm{P}_{2} \mathrm{O}_{5} /$ ha e 50-100 kg de $\mathrm{K}_{2} \mathrm{O} / \mathrm{h}$. Por outro lado, em solos ricos em matéria orgânica a dose de $\mathrm{N}$ pode ser inferior a $80 \mathrm{~kg} / \mathrm{ha}$, e em solos intensamente cultivados a dose de fósforo pode ser reduzida (SILVA et al., 2007).

O nitrogênio é um macronutriente primário que tem o maior e mais rápido efeito sobre o crescimento vegetal (MALAVOLTA, 1989). Suas funções básicas são favorecer o crescimento e a cor verde escura das plantas, promover o desenvolvimento do sistema radicular, melhorando a absorção dos outros nutrientes presentes na solução do solo, e compor a composição das proteínas de todas as plantas e animais (CAMPBEL, 2000).

Rattin, Andriolo e Witter (2003) avaliaram a acumulação de massa seca e rendimento de frutos de tomateiro cultivados em substrato com cinco doses de solução nutritiva $(23,5 ; 47,0 ; 94,0$ 117,5 e $141 \mathrm{mmol}$ de $\mathrm{N} / \mathrm{L}$ ) e verificaram um aumento na massa seca total de $375 \mathrm{~g} /$ planta para a menor dose, e de $678 \mathrm{~g} / \mathrm{planta}$, na dose de $141 \mathrm{mmol} / \mathrm{L}$ de nitrogênio. Os mesmos autores relatam um aumento linear na massa seca de frutos de 211; 216; 316; 347 e $381 \mathrm{~g} /$ planta, da menor dose para a maior.

O fósforo é um dos elementos que mais limitam a produtividade das culturas. É móvel na planta e pode se deslocar dos tecidos mais velhos para os mais novos, ocorrendo sua concentração nos tecidos em desenvolvimento (EPSTEIN; BLOOM, 2004). Na época da frutificação, as necessidades são atendidas pela mobilização das reservas.

A falta de fósforo reflete-se na diminuição da colheita, as folhas apresentam tons verde-escuro ou azul-esverdeado, sendo estes os primeiros sintomas da deficiência, desenvolvendo pigmentos avermelhados, púrpuros e marrons nas folhas (EPSTEIN; BLOOM, 2004). A deficiência do fósforo produz efeitos similares aos de deficiência de nitrogênio, com plantas de caules finos, folhas pequenas, florescimentos reduzidos e retardamento da abertura dos botões florais (COELHO; VERLENGIA, 1973).

Em experimento realizado por Silva et al. (2003) para a cultura do tomate, utilizando quatro fontes de fósforo, verificou-se que não houve diferenças entre o número de frutos, massa dos frutos grandes, pequenos, refugos, frutos rachados e com podridão apical.

No inicio do ciclo da planta, a necessidade de potássio é pequena, mas aumenta quando ela começa a se desenvolver, sendo de grande necessidade na formação dos açúcares e amido e para o transporte até os órgãos de reserva (MALAVOLTA, 1989).

O potássio é o nutriente mais extraído pelo tomateiro, e a sua deficiência torna o crescimento das plantas lento; as folhas novas afilam e as velhas apresentam amarelecimento das bordas, que vão se tornando amarronzadas e posteriormente se necrosam. O amarelecimento geralmente progride das bordas para o centro das folhas. Ocasionalmente verifica-se o aparecimento de áreas alaranjadas e brilhantes. A falta de firmeza dos frutos, em muitos casos, é também ocasionada pela deficiência de potássio (SILVA et al., 2003).

A carência de potássio afeta a qualidade e resistência dos frutos e o acúmulo de CHO, solúveis e açúcares redutores. Além disso, reflete-se na diminuição da colheita, sem que as plantas apresentem anomalias externas (MALAVOLTA, 1989). 
Em estudo realizado com dois genótipos de tomate, três doses de $\mathrm{K}_{2} \mathrm{O}$ (45, 90 e $180 \mathrm{~kg} / \mathrm{ha}$ ) e três doses de $\mathrm{P}_{2} \mathrm{O}_{5}(40,80$ e $160 \mathrm{~kg} / \mathrm{ha})$, verificou-se que houve diferença entre os genótipos estudados em relação à produção de carotenóides (CAETANO et al., 2007). Os mesmos autores relataram que não houve influência significativa das doses de fósforo e de potássio sobre os teores de ß-caroteno e açúcar, independente do genótipo estudado. Quando considerado o teor de licopeno, não foram observadas diferenças das doses de fósforo, entretanto, para o genótipo 1095 as doses de potássio apresentaram uma resposta linear e crescente (CAETANO et al., 2007).

\section{Materiais e métodos}

O trabalho foi realizado na Chácara Esperança, no município de Porto Amazonas, Paraná. A região é de clima do tipo $\mathrm{Cfb}$ - subtropical úmido, mesotérmico, verões frescos com ocorrência de geada nos meses de inverno, temperaturas médias máximas de $24^{\circ} \mathrm{C}$, mínima de $8^{\circ} \mathrm{C}$ e anual de $18^{\circ} \mathrm{C}$, com umidade relativa do ar em média de 80\% e precipitação média anual de $1.500 \mathrm{~mm}$ (WIKIPÉDIA, 2007).

As amostras de solo foram coletadas na profundidade de 0-20 cm e encaminhadas ao Laboratório de Análise de Solos da Pontifícia Universidade Católica do Paraná (PUCPR).

O preparo do solo foi feito por meio de capina manual para limpeza da área, com levantamento e nivelamento dos canteiros. Foram aplicadas $2 \mathrm{t}$ de calcário ha ${ }^{-1} 30$ dias antes do plantio. As doses de adubo foram estabelecidas a partir do recomendado para a cultura do tomate: $50 \%$ da dose recomendada $\left(86,5 \mathrm{~kg} \mathrm{ha}^{-1}\right.$ de ureia, $0,75 \mathrm{~kg} \mathrm{ha}^{-1}$ de super simples e $100 \mathrm{~kg} \mathrm{ha}^{-1}$ de cloreto de potássio), dose recomendada (173 $\mathrm{kg} \mathrm{ha}^{-1} \mathrm{de}$ ureia, $1,50 \mathrm{~kg} \mathrm{ha}^{-1}$ de super simples e $200 \mathrm{~kg} \mathrm{ha}^{-1}$ de cloreto de potássio), uma vez e meia da dose recomendada (260 $\mathrm{kg} \mathrm{ha}^{-1}$ de ureia, 2,25 $\mathrm{kg} \mathrm{ha}^{-1}$ de super simples e $300 \mathrm{~kg} \mathrm{ha}^{-1}$ de cloreto de potássio) e duas vezes a dose recomendada (346 kg ha ${ }^{-1}$ de ureia, 3,00 $\mathrm{kg} \mathrm{ha}^{-1}$ de super simples e $400 \mathrm{~kg} \mathrm{ha}^{-1}$ de cloreto de potássio). A adubação foi realizada a lanço, 30 dias antes da implantação das mudas, o adubo utilizado será o NPK.

As sementes das variedades $P$. angulata L., P. perwiana L. e P. ixocarpa L. foram semeadas em bandejas, e cada um delas foi identificada contendo o nome da variedade semeada e a data da semeadura.

O espaçamento entrelinhas foi de $1,0 \mathrm{~m}$ e entre plantas de $0,50 \mathrm{~m}$. As parcelas foram de 5,0 m x 3,0 m com uma área de 15,00 $\mathrm{m}^{2}$, com 30 plantas por parcela. Para coleta dos dados foram utilizadas dez plantas, com área útil de $7,20 \mathrm{~m}^{2}$.

Após a germinação, as mudas foram transplantadas para os canteiros quando apresentaram entre 5,0 e 7,0 cm de altura. Os dados referentes à emergência, aparecimento do primeiro botão floral, surgimento do primeiro fruto, altura de planta e início da maturação dos frutos foram obtidos por meio de diagnóstico visual, sendo acompanhados diariamente. Para a variável emergência, o período compreendeu da semeadura até o momento em que 50\% das plantas por bandeja emergiram. A altura das plantas foi medida com metro, após o início da produção.

O peso médio por fruto $(\mathrm{g})$ foi feito pesando-se individualmente dez frutos por parcela em balança de precisão.

O rendimento médio de frutos por planta $\left(\mathrm{kg} \mathrm{pl}^{-1}\right)$ consistiu da coleta de dez plantas por parcela; o padrão utilizado foi a apresentação de coloração alaranjada e quando o cálice ou "capa" que envolvem o fruto apresentaram cor amarela. Os frutos colhidos foram colocados em sacos de papel e identificados. Para a pesagem, foram retirados os cálices e separados os frutos machucados, muito maduros, danificados pela manipulação ou afetados por pragas e doença. Aqueles que apresentaram boa qualidade foram pesados em balança de precisão. O rendimento médio por área $\left(\mathrm{t} \mathrm{ha}^{-1}\right)$ foi determinado pelo somatório das colheitas realizadas durante oito semanas.

Os frutos descartados, fora do padrão estabelecido para a colheita, que se desprenderam foram recolhidos e somados às perdas ocorridas. Depois, foram pesados e seu valor anotado, compondo as perdas por variedade $\left(\mathrm{t} \mathrm{ha}^{-1}\right)$.

O delineamento experimental se deu em blocos ao acaso, com parcelas subdivididas com 12 tratamentos, sendo o fator variedade (três: $P$. angulata, $P$. peruviana e $P$. oxicarpa) aplicado às parcelas e o fator nível de adubação aplicado às subparcelas (quatro níveis). 
Os dados de rendimento médio de frutos por planta e rendimento por área foram submetidos à análise de variância. O fator dose de NPK foi submetido à análise de regressão e o fator variedade teve suas médias comparadas pelo Teste de Tukey, com significância de 5\%.

\section{Resultados}

A análise de solo apresentou 4,7 de $\mathrm{pH}, \mathrm{H}^{+}+\mathrm{Al}^{3+} 7,20 \mathrm{cmol} \mathrm{dm}^{-3}, \mathrm{Al}^{3+} 0,30 \mathrm{cmol} \mathrm{dm}^{-3}, \mathrm{Ca}^{2+} 6,19$ $\mathrm{cmol}_{\mathrm{c}} \mathrm{dm}^{-3}, \mathrm{Mg}^{2+} 3,25 \mathrm{cmol}_{\mathrm{c}} \mathrm{dm}^{-3}, \mathrm{~K}^{+} 0,50 \mathrm{cmol} \mathrm{dm}^{-3}, \mathrm{P} 14,19 \mathrm{mg} \mathrm{dm}^{-3}$, CTC de 17,14 $\mathrm{cmol}_{c}^{c} \mathrm{dm}^{-3}$, e saturação por bases $(\mathrm{V} \%) 58 \%$.

Os resultados referentes à emergência, aparecimento do primeiro botão floral, surgimento do primeiro fruto, altura de planta e início da maturação dos frutos foram obtidos por meio de diagnóstico visual e estão apresentados na Tabela 1.

Tabela 1 - Emergência, aparecimento do primeiro botão floral, primeiro fruto, altura de planta e início da maturação de frutos de $P$. angulata, $P$. peruviana e $P$. ixocarpa

\begin{tabular}{lrrr}
\hline \multirow{2}{*}{ Indicadores } & P. angulata & P. peruviana & P. ixocarpa \\
\cline { 2 - 4 } & dose $1-4$ & dose $1-4$ & dose $1-4$ \\
\hline Emergência (dap) & 15 & 18 & 24 \\
Primeiro botão floral (dap) & 44 & 43 & 50 \\
Primeiro fruto (dap) & 72 & 78 & 88 \\
Altura da planta (cm) & 137 & 156 & 123 \\
Início da maturação* & 28 & 26 & 31 \\
\hline
\end{tabular}

* Dias após o surgimento do primeiro fruto.

As variedades apresentaram o mesmo comportamento quando consideradas as doses aplicadas.

Observa-se pelos resultados que a P. oxicarpa apresentou maior período de emergência, surgimento do primeiro botão floral e fruto e início da maturação, enquanto que apresentou a menor altura de planta. Briguenti e Madeira (2007) relataram altura entre 1,00 m e 1,50 m para plantas de P. peruviana, valor próximo ao verificado neste trabalho. Observando os valores de 100 e 104 dias após o plantio para $P$. angulata e $P$. peruviana, respectivamente, estes se encontram abaixo do descrito para o início da produção de 120 a 150 dias (BRANDÃO, 2007) e de 120 a 140 dias (BRIGUENTI; MADEIRA, 2007). Entretanto, a variedade P. oxicarpa apresenta início de maturação semelhante ao estabelecido pela literatura.

O peso médio por fruto $(\mathrm{g})$ não mostrou diferenças significativas entre as variedades, sendo que P. angulata apresentou 1,44 g/fruto, $P$ oxicarpa apresentou $1,33 \mathrm{~g} /$ fruto e P. peruviana $1,15 \mathrm{~g} /$ fruto.

$\mathrm{Na}$ Figura 1 estão representadas as diferentes doses de NPK aplicadas para cada variedade.

\begin{tabular}{|c|c|c|c|c|c|}
\hline 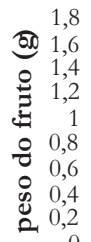 & $\begin{array}{l}\mathrm{y}=0,0675 \mathrm{x}^{2}-0,04665+1,025 \\
\mathrm{R}^{2}=0,9018\end{array}$ & 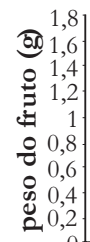 & $\underset{\substack{\mathrm{y}=-0,02 \mathrm{x}^{2}+0,324 \mathrm{x}+0,49 \\
\mathrm{R}^{2}=0,6415}}{\diamond}$ & 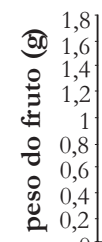 & $\sum_{y=0,1675 x^{2}+1,1085 x-0,1825}^{\square}$ \\
\hline & $\begin{array}{c}\text { dose } 1 \text { dose } 2 \text { dose } 3 \text { dose } 4 \\
\text { doses de NPK }\left(\mathbf{k g ~ h a}^{-1}\right)\end{array}$ & & $\begin{array}{c}\text { dose } 1 \text { dose } 2 \text { dose } 3 \text { dose } 4 \\
\text { doses de } \mathbf{N P K}\left(\mathbf{k g ~ h a}^{-1}\right)\end{array}$ & & $\begin{array}{c}\text { dose } 1 \text { dose } 2 \text { dose } 3 \text { dose } 4 \\
\text { doses de NPK }\left(\mathbf{k g ~ h a}^{-1}\right)\end{array}$ \\
\hline & P. angulata & & P. peruviana & & P. ixocarpa \\
\hline
\end{tabular}

Figura 1 - Peso médio de fruto para as variedades $P$. angulata, P. peruviana e P. ixocarpa submetidas a diferentes níveis de adubação NPK 
Observa-se que a variedade $P$. angulata apresentou tendência de decréscimo do peso do fruto com o aumento do volume de adubo. Para as variedades $P$. perwivana e $P$. oxicarpa, a equação polinomial de segundo grau apresentou coeficiente $\mathrm{R}^{2}$ de 0,74 e 0,61 , mostrando um aumento do peso do fruto com o aumento das doses de NPK.

Observou-se que não houve diferença entre as variedades estudadas na produção de frutos por

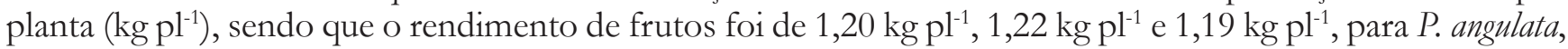
P. oxicarpa e $P$. peruviana, respectivamente.

O efeito das diferentes doses de NPK estudadas (Figura 2) para a variedade P. angulata foi irregular e variável, segundo a curva de resposta encontrada $\left(\mathrm{R}^{2}\right.$ de 0,42$)$. Para as variedades $P$. peruviana e P. oxicarpa, o efeito das doses de adubo foi mais regular, indicando com maior precisão aumento do rendimento de frutos por planta na variedade $P$. peruviana e tendência de redução do rendimento por planta com o aumento das doses de adubo.

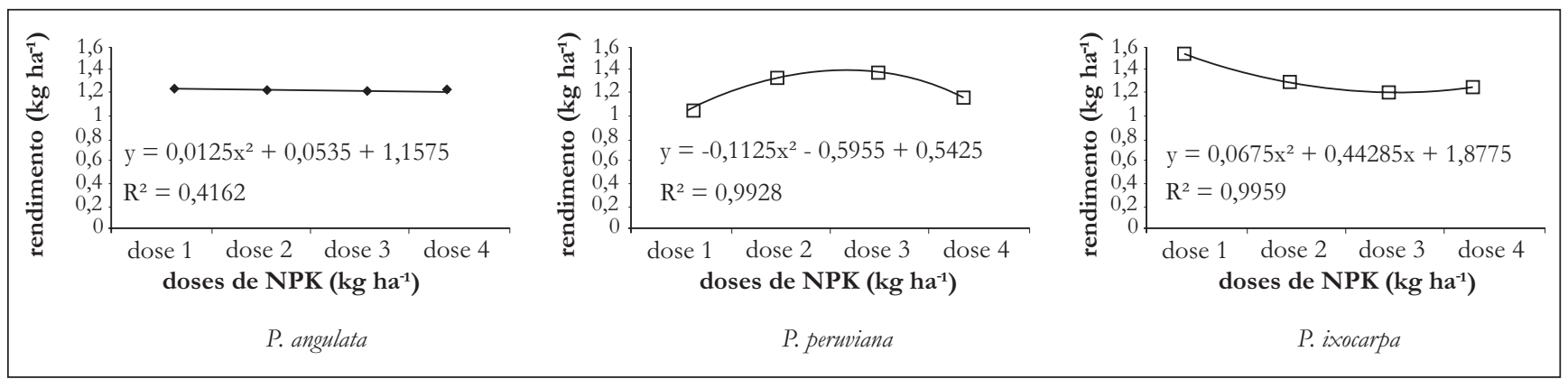

Figura 2 - Rendimento médio $\left(\mathrm{kg} \mathrm{pl}^{-1}\right)$ de frutos por planta das variedades P. angulata, P. peruviana e P. ixocarpa submetidas a diferentes volumes de adubação NPK

Estes resultados diferem daquele obtido por Rattin, Andriolo e Witter (2003), que verificaram aumento de massa de frutos de tomateiro cultivados com o aumento da dose de nutrientes em solução nutritiva.

Os resultados do rendimento médio de frutos por hectare também não mostraram diferenças significativas entre as variedades. A P. peruviana apresentou o maior rendimento, com 24,78 t ha- ${ }^{1}$. A P. oxicarpa apresentou 19,12 $\mathrm{t} \mathrm{ha-}^{-1}$ e a P. angulata, 15,78 $\mathrm{t} \mathrm{ha}^{-1}$.

O efeito das doses de NPK sobre o rendimento médio de frutos (Figura 3) foi irregular e variável para $P$. angulata e $P$. oxicarpa $\left(\mathrm{R}^{2}\right.$ de 0,43 e 0,19$)$. Somente a $P$. peruviana apresentou maior precisão, indicando que o aumento da dose de NPK aumenta o rendimento dessa variedade.

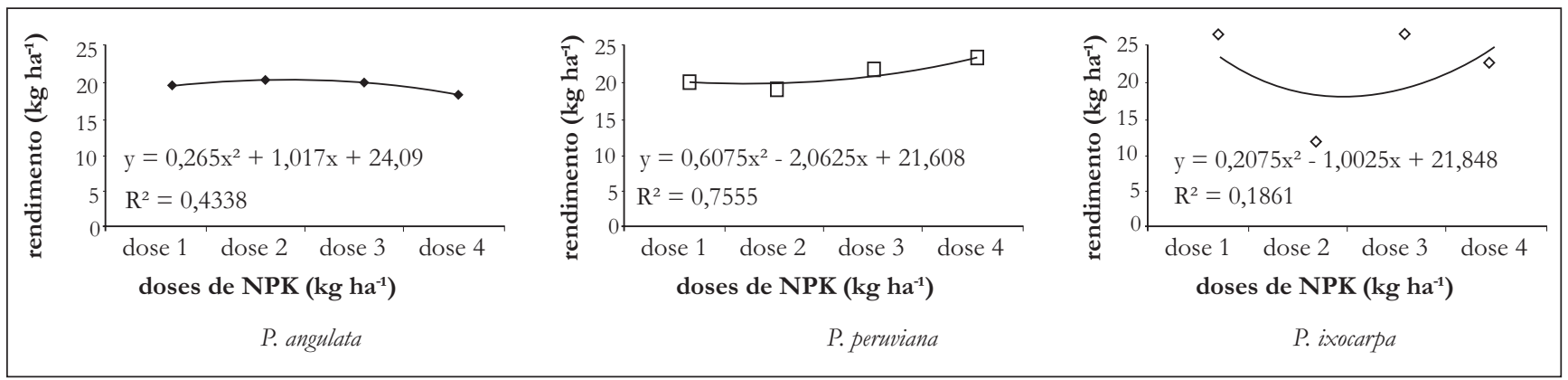

Figura 3 - Rendimento médio $\left(\mathrm{t} \mathrm{ha}^{-1}\right)$ de frutos por planta das variedades P. angulata, P. perwviana e P. ixocarpa submetidas a diferentes volumes de adubação NPK

Resultado semelhante para a cultura de tomate foi observado por Silva et al. (2003) que testaram o efeito de diferentes doses de P na produção de frutos de tomate. Santos et al. (2001) também não encontraram diferença significativa para diferentes volumes de adubação na produtividade comercial de frutos; entretanto, verificaram diferença entre cultivares de tomate salada, sugerindo que a fertilidade inicial do solo encontrava-se elevada. De acordo com a análise do solo, os teores de $\mathrm{P}, \mathrm{K}^{+}, \mathrm{Ca}^{2+}$ e $\mathrm{Mg}^{2+}$ apresentaram-se altos, podendo-se considerar que o grau de fertilidade da área experimental foi considerado bom. 
Os resultados mostraram que não houve diferenças significativas entre as variedades estudadas, apresentando $0,80 \mathrm{~kg} \mathrm{ha}^{-1}, 0,42 \mathrm{~kg} \mathrm{ha}^{-1}$ e $0,22 \mathrm{~kg} \mathrm{ha}^{-1}$ de perdas de frutos para $P$. angulata, $P$. peruviana e $P$. oxicarpa, respectivamente.

O efeito das diferentes doses de adubo indicou aumento nas perdas de frutos de P. angulata e $P$. peruviana $\left(\mathrm{R}^{2}\right.$ de 0,79 e 0,99$)$, enquanto que $P$. oxicarpa $\left(\mathrm{R}^{2}\right.$ de 0,77$)$ apresentou redução nas perdas com o aumento das doses de adubo. Os fatores que influenciam a perda de frutos são os tratos fitossanitários como a monda, poda, densidade de plantas, condições climáticas, como chuvas e temperaturas elevadas, e as condições de solo, como a fertilidade.

Observou-se que, no período de desenvolvimento da cultura (primavera e verão), houve o surgimento de pragas, principalmente de percevejos, e a presença de doença. As variedades de fisalis, para as condições ambientais da área de estudo, apresentaram suscetibilidade aos patógenos e pragas (Figura 4).

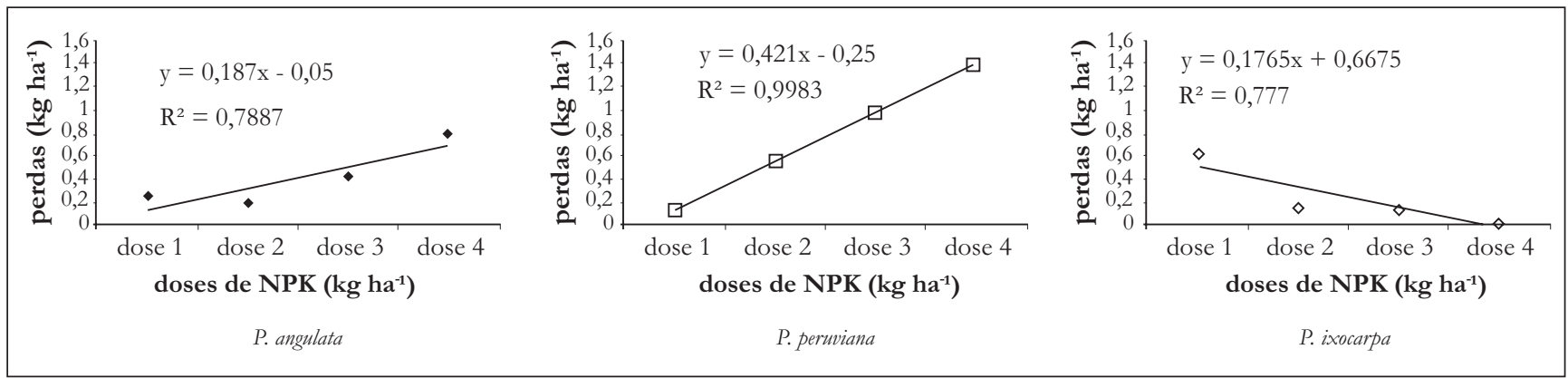

Figura 4 - Perdas médias de frutos $\left(\mathrm{t} \mathrm{ha}^{-1}\right)$ das variedades $P$. angulata, $P$. peruviana e $P$. ixocarpa submetidas a diferentes volumes de adubação NPK

Este fato poderia resultar na perda de frutos. Outro fator que influencia na perda de frutos é a adubação nitrogenada, que estimula o desenvolvimento de folhas e caules, tornando a cultura mais densa, menos ensolarada e, portanto, mais propensa às doenças.

\section{Conclusões}

- A adubação NPK mostrou diferenças entre as curvas de respostas para as variedades estudadas;

- As variedades estudadas não mostraram diferenças para o peso de fruto, rendimento por planta e rendimento por hectare; porém, é necessário dar continuidade à avaliação da cultura para observar o comportamento dela durante os períodos de produtividade, pois as variedades apresentam um ciclo contínuo de produtividade quando feito um bom manejo.

\section{Referências}

BRANDÃO V. Physalis. Disponível em: <http://correiogourmand.com.br/info_glossario_produtos_ alimentos_frutas_frutos_physalis.htm>. Acesso em: 10 ago. 2007.

BRIGUENTI, A. F.; MADEIRA, F. C. Physalis, uma alternativa para o fruticultor. Jornal da Fruta, ano 15, n. 187, p. 12-13, 2007.

CAETANO, E. et al. Influência de doses de potássio e fósforo nos teores de carotenóides em genótipos industriais de tomateiro. In: SIMPÓSIO DE PESQUISA, 2., SEMIC - SEMINÁRIO DE INICIAÇÃO CIENTÍFICA DA UNIFENAS, 5., 2007, Alfenas. Anais... Alfenas, MG: UNIFENAS, 2007. Disponível em: <http://www.unifenas.br/pesquisa/semic/visemic\&iisimposiodepesquisa/anais/resumos/agronomia/1041. pdf>. Acesso em: 27 ago. 2007. 
CAMPBELL, M. K. Bioquímica. 3. ed. Porto Alegre: Artmed, 2000.

COELHO, F. S.; VERLENGIA, F. Fertilidade do solo. Campinas: Instituto Campineiro de Ensino Agrícola, 1973.

EPSTEIN, E.; BLOOM, A. Nutrição mineral de plantas: princípios e perspectivas. Tradução de Maria Edna Tenório Nunes. Londrina: Plantas, 2004.

FROTA, M. C. Novidade no pomar. 2005. Disponível em: <http://revistagloborural.globo.com/ GloboR ural/0,6993,EEC972755-1641,00.html>. Acesso em: 13 ago. 2007.

GUERREIRO, L. Cultivo de physalis. Rede de Tecnologia do Rio de Janeiro - REDETEC. nov. 2006. Disponível em: <http://sbrt.ibict.br/upload/sbrt3882>. Acesso em: 15 ago. 2007.

LORENZI, H. Manual de identificação e controle de plantas daninhas: plantio direto e convencional. 5. ed. Nova Odessa: Plantarum, 2000.

MALAVOLTA, E. ABC da adubação. 5. ed. São Paulo: Agronômica Ceres, 1989.

PHYSALIS. O processo produtivo. Disponível em: < http://www.embaixadacolombia.pt/physalis.html>. Acesso em: 15 ago. 2007.

RATTIN, J. E.; ANDRIOLO, J. J.; WITTER, M. Acumulação de massa seca e rendimento de frutos de tomateiro cultivado em substrato com cinco doses de solução nutritiva. Horticultura Brasileira, v. 21, n. 1, p. 26-30, 2003.

SANTOS, P. R. Z.; PEREIRA, A. S.; FREIRE, C. J. S. Cultivar e adubação NPK na produção de tomate salada. Horticultura Brasileira, v. 19, n. 1, p. 35-39, 2001.

SILVA, H. R. et al. Efeito da fertirrigação adubação fosfatada no cultivo do tomateiro longa vida sob cultivo protegido. Horticultura Brasileira, v. 21, n. 2, 2003. Disponível em: <http:// www.feagri.unicamp.br/tomates/ pdfs/cpna2000C.pdf>. Acesso em: 15 ago. 2007.

SILVA, J. B. C. da et al. Cultivo de tomate para industrialização. Disponível em: <http://www.cnph. embrapa.br/sistprod/tomate/index.htm>. Acesso em: 27 ago. 2007.

ESTAÇÃO EXPERIMENTAL SERRA LUZIA - SL. Physalis. Disponível em: < http:/ /www. frutasexoticas. com.br /physalis.htm>. Acesso em: 10 ago. 2007.

WIKIPEDIA Physalis. Disponível em: <http://pt.wikipedia.org/wiki/Physalis>. Acesso em: 10 ago. 2007.

Recebido: 03/11/2009

Received: 11/03/2009

Aprovado: 22/12/2009

Approved: 12/22/2009 